\title{
Pathophysiological roles of microvascular alterations in pulmonary inflammatory diseases: possible implications of tumor necrosis factor-alpha and CXC chemokines
}

\author{
Kanami Orihara \\ Akio Matsuda \\ Department of Allergy and \\ Immunology, National Research \\ Institute for Child Health \\ and Development, Tokyo, Japan
}

Correspondence: Akio Matsuda Department of Allergy and Immunology, National Research Institute for Child Health and Development, 2-10-I Okura, Setagaya-ku, Tokyo, I57-8535, Japan

$\mathrm{Tel}+8 \mathrm{I} 354947 \mathrm{I} 20$

Fax +8I 354947028

Email amatsuda@nch.go.jp

\begin{abstract}
Chronic obstructive pulmonary disease (COPD) and bronchial asthma are common respiratory diseases that are caused by chronic inflammation of the airways. Although these diseases are mediated by substantially distinct immunological reactions, especially in mild cases, they both show increased numbers of neutrophils, increased production of tumor necrosis factor-alpha (TNF- $\alpha$ ) and poor responses to corticosteroids, particularly in patients with severe diseases. These immunological alterations may contribute strongly to airway structural changes, commonly referred to as airway remodeling. Microvascular alterations, a component of airway remodeling and caused by chronic inflammation, are observed and appear to be clinically involved in both diseases. It has been well established that vascular endothelial growth factor (VEGF) plays important roles in the airway microvascular alterations in mild and moderate cases of both diseases, but any role that VEGF might play in severe cases of these diseases remains unclear. Here, we review recent research findings, including our own data, and discuss the possibility that TNF- $\alpha$ and its associated CXC chemokines play roles in microvascular alterations that are even more crucial than those of VEGF in patients with severe COPD or asthma.
\end{abstract}

Keywords: TNF- $\alpha$, CXC chemokines, corticosteroid, pulmonary microvessels, COPD, asthma

\section{Introduction}

Chronic obstructive pulmonary disease (COPD) and bronchial asthma are common respiratory diseases that are caused by chronic or excessive inflammation of the airways.

Chronic inflammation of the airways in these diseases is mediated by substantially distinct immunological reactions, with different patterns of inflammatory cells and mediators, particularly in patients with mild to moderate diseases. The inflammatory process in COPD is characterized by increases in macrophages, neutrophils and CD ${ }^{+}$ T cells (Grashoff et al 1997; Jeffery 2000; Hogg et al 2004), as well as important mediators such as interleukin 8 (IL-8) and tumor necrosis factor-alpha (TNF- $\alpha$ ) (Chung 2001). On the other hand, the inflammatory process in asthma is characterized by increased eosinophils, mast cells and type-2 helper T (Th2) cells, which produce IL-4, -5 and -13 (Busse and Lemanske 2001).

These immunological differences between COPD and asthma are considered to be associated with differences in the efficacy of inhaled corticosteroid (ICS) therapy as well as airway structural changes (ie, airway remodeling) between these diseases. Among the components of airway remodeling, microvascular alterations have been 
increasingly noted in both diseases. ICS is known to be the most effective therapy available for treatment of asthma, particularly in patients with mild to moderate disease (Barnes et al 1998). Indeed, numerous studies showing the effects of ICS on bronchial biopsy and bronchoalveolar lavage samples in patients with asthma have demonstrated that the increased numbers of $\mathrm{CD}^{+} \mathrm{T}$ cells, eosinophils and mast cells and increased vascularity seen in this disease are substantially reduced by ICS (Laitinen et al 1991; Bentley et al 1996; Chetta et al 2003). In contrast, patients with COPD respond poorly to ICS treatment. It is generally assumed that neutrophils are less sensitive to corticosteroids than are eosinophils and T cells (Schleimer 1990). These differences in the responsiveness of activated inflammatory cells help to explain why ICS treatment has been more beneficial for patients with asthma than COPD. Furthermore, these differences in corticosteroid responsiveness between COPD and asthma can also be used for differential diagnosis.

However, it has now become evident that these immunological profiles of both diseases are altered during progression from mild to severe diseases. In severe COPD, the number of macrophages, activated neutrophils, natural killer lymphocytes in the subepithelium are further increased in comparison with subjects with mild to moderate diseases (Di Stefano et al 1998). Furthermore, bronchial inflammation in severe COPD is characterized by lower numbers of $\mathrm{CD}^{+}$and $\mathrm{CD}^{+} \mathrm{T}$ cells in comparison with subjects with mild to moderate diseases (Di Stefano et al 2001). These findings show a shift of inflammatory profiles involved in severe diseases. On the other hand, some of the common features of COPD and asthma, including increased numbers of neutrophils, increased amounts of TNF- $\alpha$ and poor responses to corticosteroids, are seen in patients with both severe cases (Howarth et al 2005; Kamath et al 2005; Berry et al 2006; Mann and Chung 2006; Barnes 2007, 2008). This not only makes differential diagnosis complicated but also has important implications for the development of therapeutic strategies for patients with severe COPD or asthma.

In this review, we focus on the role of microvessels in the development of airway obstructive diseases, including COPD and asthma, and discuss how the immunological features of patients with severe diseases affect the microvascular alterations in both diseases. Notably, this article highlights the possible crucial involvement of TNF- $\alpha$ and CXC chemokines, rather than vascular endothelial growth factor (VEGF), in the microvascular alterations seen in COPD and asthma, particularly in severe cases.

\section{VEGF and microvascular alterations in COPD and asthma Vascular regulation by VEGF}

VEGF was originally identified as a vascular permeability factor based on its ability to cause tissue edema (Senger et al 1993). Subsequently, VEGF has been widely recognized as one of the most potent angiogenic factors, mediating the growth of new vessels from preexisting ones (Risau 1997). The process of angiogenesis is a complex and highly orchestrated series of multiple events, including proliferation, migration, survival and tube formation of vascular endothelial cells. VEGF has several isoforms that are produced by alternative splicing of a single VEGF gene (Ferrara et al 2003) and act via their specific receptors, VEGFR1/Flt-1 and/or VEGFR2/KDR/Flk-1, on vascular endothelial cells (Yancopoulos et al 2000).

\section{VEGF in COPD}

Both functional (increased microvascular permeability, edema and inflammatory cell recruitment) and structural (angiogenesis) changes in the airway microvessels are seen in chronic airway inflammatory conditions. Although microvascular alterations in asthma are well documented, as described below, those in COPD have not been fully elucidated yet. An early report indicated that the alveolar septa in emphysema appear to be remarkably thin and almost avascular (Liebow 1959). Later, Abman and Voelkel et al demonstrated that lung blood vessels actively promote normal alveolar development and contribute to the maintenance of alveolar structure (Jakkula et al 2000; Kasahara et al 2000; Abman 2001). These studies indicated that a reduction in the blood supply of the microvessels might induce the destruction of alveolar septa. Indeed, VEGF concentration in induced sputum was significantly reduced in emphysema (Kanazawa et al 2003). Similarly, VEGFR2 expression was also decreased in total lung extracts of emphysema patients (Kasahara et al 2000). On the contrary, VEGF concentration in induced sputum was significantly elevated in chronic bronchitis patients, although those levels were lower than those in asthmatic patients. Similar to the pattern seen in asthmatics, chronic bronchitis patients show an inverse correlation between the concentration of VEGF and the forced expiratory volume in one second $\left(\mathrm{FEV}_{1}\right)$. In contrast, the concentration of VEGF correlated positively with $\mathrm{FEV}_{1}$ in emphysema patients, probably due to VEGF-mediated maintenance of the alveolar structure. Thus, the VEGF level in the lung is considered to explain the pathologies in COPD. 


\section{VEGF in asthma}

To date, numerous studies have shown that VEGF is critically involved in the microvascular alterations observed in asthma. Exaggerated levels of VEGF have been detected in asthmatic airways compared with in the airways in normal control subjects (Hoshino et al 2001a, b; Asai et al 2002; Kanazawa et al 2002; Asai et al 2003; Chetta et al 2005). VEGF levels in the airways show a positive correlation with airway inflammation (Lee and Lee 2001) and correlate inversely with lung function (Asai et al 2003), suggesting that VEGF plays important roles in the pathogenesis of asthma. In a murine model of bronchial asthma, lung-specific and inducible overexpression of VEGF was shown to enhance not only angiogenesis, but also Th2 inflammation and hyperresponsiveness of the airways (Lee et al 2004). Importantly, the biological effects of overexpressed VEGF, such as angiogenesis, were reversed by cessation of the transgenic VEGF elaboration in that murine model, suggesting that the effects of VEGF on the development of airway hypervascularity are dependent upon its expression level. In humans, ICS treatment was found to effectively reduce VEGF production in the airways, thereby reducing the submucosal vascularity (Asai et al 2002; Chetta et al 2003, 2005; Abdel-Rahman et al 2006; Feltis et al 2007). However, it should be noted that these studies were restricted to cases of mild to moderate asthma. Therefore, any role of VEGF in severe refractory asthma remains unclear.

\section{CXC chemokines and microvascular alterations in COPD and asthma Vascular regulation by CXC chemokines}

Chemokines convey specificity to the leukocyte recruitment cascade by inducing leukocyte subtypes to adhere to endothelium and activate so as to play an essential role in the inflammatory process. Chemokines are divided into two major subfamilies, CXC and CC, based on the position of the first two conserved cysteine residues: the two cysteines are separated by a non-conserved amino acid in CXC chemokines, whereas they are adjacent in CC chemokines (Zlotnik and Yoshie 2000). CXC chemokines are further subdivided into ELR and non-ELR types based on the presence or absence of a glutamic acid, leucine and arginine sequence adjacent and $\mathrm{N}$-terminal to the CXC motif. Members of the CXC chemokines with an ELR-motif include growth-related oncogene alpha (Gro- $\alpha$ )/CXC ligand 1 (CXCL1), Gro$\beta / C X C L 2$, Gro- $\gamma /$ CXCL3, epithelial neutrophil activating peptide 78 (ENA78)/CXCL5, granulocyte chemotactic protein 2 (GCP2)/CXCL6 and IL-8/CXCL8. These molecules act as major chemoattractants for neutrophils. In contrast, members of the CXC chemokines without an ELR-motif include monokine induced by IFN- $\gamma$ (MIG)/CXCL9, interferon (IFN)-inducible protein 10 (IP-10)/CXCL10 and IFN-inducible $\mathrm{T}$ cell alpha chemoattractant (I-TAC)/ CXCL11, and these chemokines act as chemoattractants for Th1 cells.

These two subtypes of CXC chemokines show disparate properties regarding angiogenesis and can be divided into an angiogenic ELR-positive type and an angiostatic ELRnegative type. The angiogenic activity of ELR-positive CXC chemokines, such as IL-8, is mediated via their common receptor, CXC chemokine receptor 2 (CXCR2), which is expressed on microvascular endothelial cells (Addison et al 2000; Heidemann et al 2003). These chemokines are thus referred to as "CXCR2 chemokines" throughout this manuscript. In contrast, the angiostatic activity of ELRnegative CXC chemokines, such as IP-10, is mediated via their common receptor, CXCR3, which is also expressed on microvascular endothelial cells (Lasagni et al 2003). These chemokines are thus referred to as "CXCR3 chemokines" throughout this manuscript.

The process of angiogenesis is known to be regulated by a complex interaction of activators and inhibitors, and inappropriate production of these factors may cause aberrant angiogenesis. As a matter of fact, a recent report indicated the importance of the CXC chemokine-mediated angiogenic/ angiostatic balance in bleomycin-induced pulmonary fibrosis. The study clearly showed that a CXCR3 chemokine, I-TAC, inhibits IL-8-mediated angiogenesis (Burdick et al 2005).

\section{CXC chemokines in COPD}

In contrast to asthma, $\mathrm{CD} 4^{+} \mathrm{T}$ cells that accumulate in the airways of patients with COPD are mainly Th1 cells producing IFN- $\gamma$ (Majori et al 1999; Panina-Bordignon et al 2001). CXCR3 chemokines such as IP-10 are induced by IFN- $\gamma$ from a variety of cell types (Sauty et al 1999; Hardaker et al 2004), including endothelial cells (Marx et al 2000; Matsuda et al 2008a). Furthermore, studies of peripheral lung lymphocytes from cigarette smokers with emphysema indicated that their $\mathrm{CD} 4^{+} \mathrm{T}$ cells are not only polarized to the Th1 phenotype, but also secreted more CXCR3 chemokines compared to those in the group without emphysema (Grumelli et al 2004). Immunoreactivity for IP-10 was detected in the airway epithelium (Saetta et al 2002) and smooth muscle (Hardaker et al 2004) of COPD patients but not in normal control subjects. Furthermore, in response to IP-10, but not IFN- $\gamma$, lung macrophages secreted matrix 
metalloproteinase-12 (MMP12), a potent elastin-degrading enzyme that causes tissue destruction and has been linked to emphysema (Grumelli et al 2004). Thus, CXCR3 chemokines are considered to be involved in the pathogenesis of COPD, particularly in emphysema.

As described above, these chemokines also act as potent anti-angiogenic factors. In addition to reduction of VEGF, overproduction of CXCR3 chemokines may promote avascularity of the emphysema lung (Kanazawa et al 2003). However, it is evident that IL-8, a proangiogenic CXCR2 chemokine, is also predominant in patients with COPD (Pesci et al 1998). TNF- $\alpha$ appears to play a role in the pathogenesis of COPD (Chung 2001), and the levels of TNF- $\alpha$ are further upregulated in severe COPD patients (Hacievliyagil et al 2006) and patients experiencing acute COPD exacerbation (Aaron et al 2001). Human airway smooth muscle cells (Hardaker et al 2004), epithelial cells (Sauty et al 1999) and microvascular endothelial cells (Matsuda et al 2008a) treated simultaneously with IFN- $\gamma$ and TNF- $\alpha$ demonstrated robust increases in the production of CXCR3 chemokines compared with cells treated with either stimulus alone. These findings strongly suggest that overproduction of CXCR3 chemokines induced by the combination of IFN- $\gamma$ and TNF- $\alpha$ is more involved in the pathogenesis of severe COPD, at least in part through their excess anti-angiogenic activity, than is CXCR2 chemokinemediated angiogenic activity. Importantly, proliferation and tube formation by human lung microvascular endothelial cells was almost completely inhibited in the co-presence of IFN- $\gamma$ and TNF- $\alpha$ in vitro, even in the presence of sufficient amounts of recombinant VEGF (Matsuda et al 2008a). This observation is also fully compatible with the pathological findings of avascularity in emphysema. Thus, CXCR3 chemokines might be involved in the aberrant vascularity, which is responsible for destruction of the alveolar septa, observed in patients with severe emphysema, as well as their chemotactic properties.

As described above, levels of CXCR2 ligands, such as IL-8 and ENA78/CXCL5 are elevated in bronchoalveolar lavage fluid of COPD patients (Pesci et al 1998). These chemokines recruit and activate neutrophils via their receptor CXCR2 expressed on neutrophils. Therefore, small molecule inhibitors of CXCR2 such as SB225002 are likely to be useful for attenuating CXCR2 ligands-mediated neutrophilic inflammation in the COPD airway (Hay and Sarau 2001; Barnes 2003). However, considering especially for the CXC chemokines-mediated angiogenic-angiostatic balance in the airway, CXCR2 antagonists are likely to be more useful for severe asthma than for severe COPD, as discussed below.

\section{CXC chemokines in asthma}

Although VEGF-mediated airway hypervascularity in patients with asthma is responsive to corticosteroid treatment (Asai et al 2002; Chetta et al 2003, 2005; Abdel-Rahman et al 2006; Feltis et al 2007), several clinical studies have also demonstrated that airway hypervascularity is seen in fatal (Wilson 2000) and severe corticosteroid-dependent asthma (Vrugt et al 2000) and even in patients treated with ICS for more than 5 years (Tanaka et al 2003). Of note, structural abnormalities of airway remodeling are present in children with severe asthma. Tillie-Leblond et al studied bronchial biopsies from severe asthma with persistent symptoms in two groups of children with or without persistent airflow obstructive pattern. Persistent obstructive pattern was defined as a FEV 1 less than $80 \%$ of the predicted value after a course of systemic corticosteroids and no significant improvement after bronchodilator. They demonstrated that an increase in the density of the vascular network was more pronounced in children with persistent airflow obstruction than in children without persistent airflow obstruction (TillieLeblond et al 2008). These observations indicate that airway hypervascularity in severe asthma is poorly responsive to corticosteroid treatment and is clinically involved in lung function. Therefore, another possible explanation of the cause besides VEGF might be the presence of hypervascularity in severely asthmatic airways. Recently, we have shown that, only in the presence of TNF- $\alpha$, IL-4/13 and IFN- $\gamma$ reciprocally regulate angiogenesis by human lung microvascular endothelial cells in vitro through autocrine synthesis of CXCR2 and CXCR3 chemokines, respectively (Matsuda et al 2008a). It should be noted that CXCR2 chemokineinduced angiogenesis is independent of VEGF. These results highlight the importance of TNF- $\alpha$ for VEGF-independent/ CXCR2 chemokine family-dependent angiogenesis. While both IL- 8 and TNF- $\alpha$ are abundant in the severely asthmatic airways (Howarth et al 2005; Berry et al 2006; Mann and Chung 2006; Silvestri et al 2006), airway hypervascularity in severe asthma might be primarily due to TNF- $\alpha$ and CXCR2 chemokines rather than mediation by VEGF. Furthermore, corticosteroid therapies would offer little hope for improving TNF- $\alpha /$ CXCR 2 chemokine-associated angiogenesis, because corticosteroid has scant effect on TNF- $\alpha$-induced CXCR2 chemokine production by human lung microvascular endothelial cells (Matsuda et al 2008b). Therefore, CXCR2 antagonists are likely to be useful for attenuating 
TNF- $\alpha /$ CXCR2 chemokines-mediated hypervascularity in addition to blocking chemokine-induced neutrophil chemotaxis and activation (Barnes 2007) in patients with severe asthma, which are characterized by elevated levels of TNF- $\alpha$ and neutrophilic inflammation.

\section{Corticosteroid actions in pulmonary microvascular endothelial cells}

In the context discussed above, TNF- $\alpha$-associated CXC chemokines appear to play critical roles in vascular alterations in both COPD and asthma, especially in severe cases. In addition to these structural alterations, TNF- $\alpha$ also plays crucial roles in vascular functions by regulating leukocyte recruitment into local inflamed tissues (Kelly et al 2007), which is an important step in the development of acute and chronic inflammatory responses (Carlos and Harlan 1994). This recruitment is a dynamic process requiring interactions between leukocytes and the vascular endothelium. To that end, TNF- $\alpha$ induces endothelial cell expression of various molecules, including intercellular adhesion molecule 1 (ICAM-1) and vascular cell adhesion molecule 1 (VCAM-1), that are essential for those interactions (Cotran and Pober 1990). Recently, we demonstrated that TNF- $\alpha$-induced expressions of ICAM-1 and VCAM-1 on human lung microvascular endothelial cells were further enhanced by corticosteroid treatment (Matsuda et al 2008b). Correspondingly, adhesion of eosinophils and neutrophils to these cells was also enhanced by corticosteroid treatment, suggesting that instead of inhibiting the recruitment of inflammatory cells into local inflamed tissues, ICS therapies actually promote their adhesion, probably via upregulation of cell-surface expression of ICAM-1 and VCAM-1 on the endothelium. Indeed, in severe asthma, a highly significant correlation was found between the total number of vessels and the vessels expressing ICAM-1 in biopsy specimens (Vrugt et al 2000), which supports the hypothesis that ICS therapies are not effective in reducing ICAM-1 expression on the endothelium. While TNF- $\alpha$-induced IP-10 expression in microvascular endothelial cells is further enhanced by corticosteroid treatment (Matsuda et al 2008b), ICS therapies might not be effective in curing the avascularity observed in emphysema patients. Together, ICS therapies offer little expectation for improving TNF- $\alpha$-mediated pulmonary microvascular alterations, including CXCR2 chemokine-mediated angiogenesis, CXCR3 chemokine-mediated avascularity and inflammatory cell recruitment. Moreover, these microvascular alterations mediated by TNF- $\alpha$ might be clinically associated with the development of COPD and also asthma.
TNF- $\alpha$ is a major therapeutic target in chronic inflammatory diseases including rheumatoid arthritis and Crohn's diseases (Feldmann and Maini 2003). Recently, clinical trials of antiTNF-therapy have demonstrated good improvement in lung function and airway hyperresponsiveness in severe refractory asthma (Howarth et al 2005; Berry et al 2006). Thus, it is now recognized that anti-TNF therapies are likely to become an important treatment option for patients with refractory asthma (Holgate et al 2006). The effectiveness of anti-TNF therapies in such patients may be at least partly due to the prevention of TNF- $\alpha$-activated vascular inflammation. However, a clinical study has demonstrated that subjects with moderate to severe COPD did not benefit from treatment with anti-TNF therapy (Rennard et al 2007). It is currently unclear why the anti-TNF therapy is more effective for severe asthma than for severe COPD. Although further studies are needed to elucidate the pathological roles in TNF- $\alpha$ of severe COPD and asthma, respectively, differences in increased number of blood vessels, which are major targets of TNF- $\alpha$, in the airway between these diseases (ie, avascularity in severe COPD and hypervascularity in severe asthma) may reflect to the efficacy of anti-TNF therapy.

\section{Possibility of microvessel-targeted treatment options in COPD and asthma}

The impact of corticosteroids on pulmonary microvascular endothelial cells is apparently distinct from that on other airway structural cells, including epithelial cells, smooth muscle cells and fibroblasts, in which TNF- $\alpha$-induced expressions of chemokines and cellular adhesion molecules are significantly downregulated by corticosteroid treatment (Spoelstra et al 2000; Issa et al 2007; Newton et al 2007; Matsuda et al 2008b). Increased amounts of TNF- $\alpha$ and poor responses to corticosteroids are common features observed in both COPD and severe asthma. Therefore, TNF- $\alpha-$ mediated responses of pulmonary microvessels, such as inflammatory cell recruitment into inflamed tissues and inflammatory chemokine expression, may at least partially explain the corticosteroid refractoriness in these diseases. In this context, as a new therapeutic strategy for patients with severe COPD or asthma, the near future holds the possibility of direct microvessel-targeted topical treatment options.

ICAM-1 is a potential candidate molecule for targeted treatment of patients with severe COPD or asthma. Although there have not been any clinical trials of anti-ICAM-1 therapy for patients with severe COPD or asthma, in a rat model of extrinsic asthma, administration of monoclonal antibody 
to ICAM-1 significantly attenuated both the early and late responses of bronchial asthma (Nagase et al 1995). In ICAM-1-deficient mice, significant inhibition of lung tissue eosinophil recruitment (Broide et al 1998) and airway hyperreactivity (Hatfield et al 1997) were observed after allergen challenge. ICAM-1 is expressed not only on the inflamed endothelium but also on inflamed fibroblasts and epithelium in the airways. Respiratory viruses are a major cause of exacerbations of both COPD and asthma, and the most prevalent viruses detected during exacerbations are the rhinoviruses (Nicholson et al 1993; Johnston et al 1995; Seemungal et al 2000; Rohde et al 2003). Since ICAM-1 is a major receptor for rhinovirus (Staunton et al 1989), anti-ICAM-1 therapy might be effective in preventing rhinovirus-induced exacerbations of these diseases in addition to attenuating inflammatory cell recruitment into local inflamed tissues.

Alternatively, as described above, CXCR3 and CXCR2 might be potential candidate molecules for targeted treatment of patients with severe COPD and asthma, respectively. Anti-CXCR3 therapy might bring about improvement of CXCR3 chemokine-induced avascularity in addition to attenuating Th1 inflammation in emphysema patients. In contrast, anti-CXCR2 therapy might lead to improvement of
CXCR2 chemokine-induced hypervascularity in addition to neutrophilic inflammation in severe asthmatics.

\section{Conclusions}

COPD and asthma are chronic inflammatory diseases of the airways, and characteristic structural alterations in the airways are observed in each disease, including microvascular alterations. These microvascular alterations caused by chronic inflammation appear to be clinically involved in both diseases. Although the type of inflammation is quite different between COPD and asthma, especially in patients with mild to moderate disease, increased amounts of TNF- $\alpha$, neutrophilic inflammation and poor responses to corticosteroids are the common features in patients with severe COPD or asthma.

Figure 1 presents an overview of microvascular alterations in pulmonary inflammatory diseases discussed in this review. In COPD, VEGF concentration in chronic bronchitis patients is significantly elevated, although those levels are lower than those in asthmatic patients. However, increased numbers of microvessels (ie, angiogenesis) in the airway of COPD patients have not been established. Some COPD patients with emphysema show rather reduced production of VEGF,

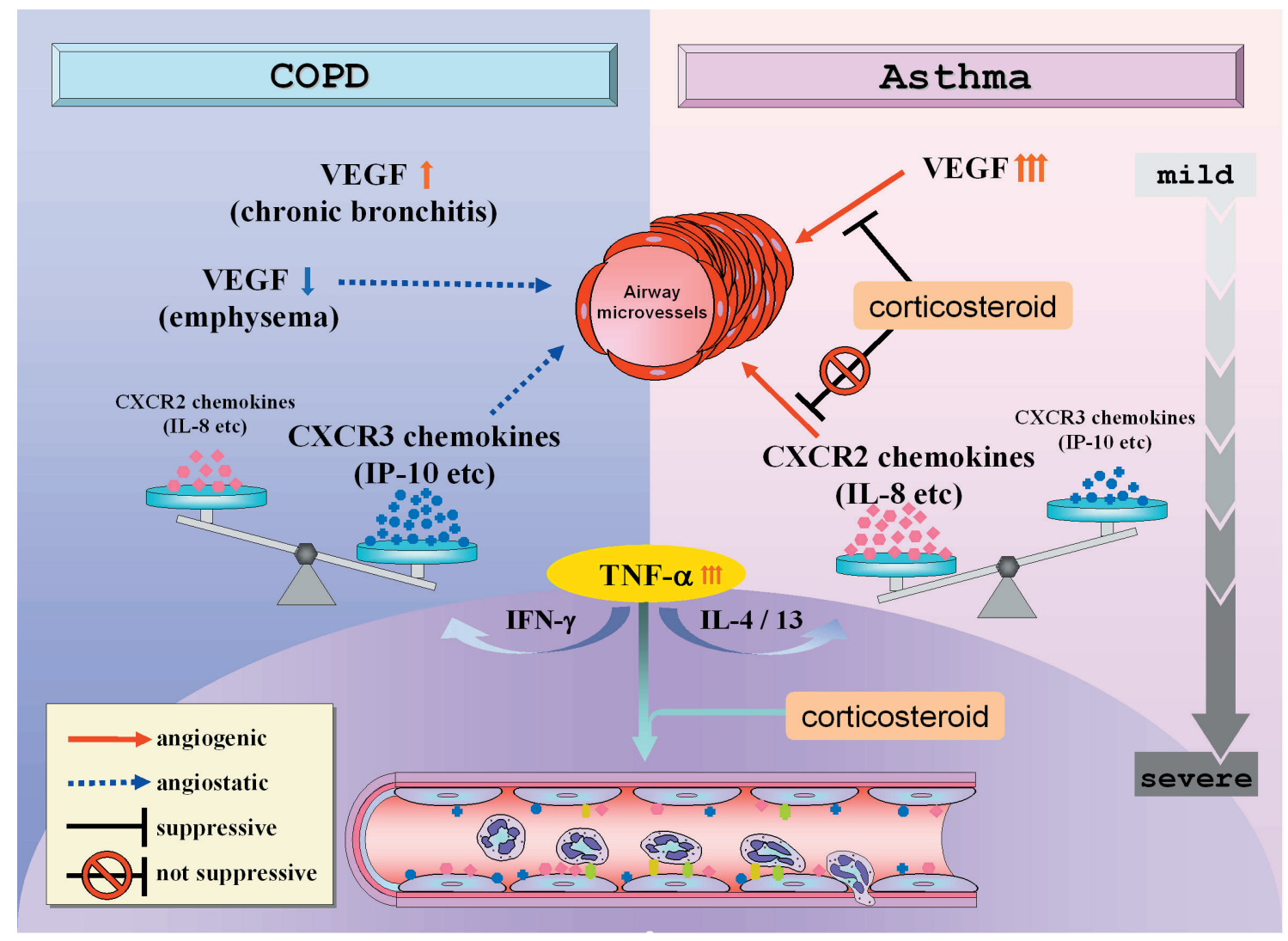

Figure I An overview of microvascular alterations in pulmonary inflammatory diseases. 
resulting in the destruction of alveolar septa. In contrast, in mild to moderate asthma, increased production of VEGF in the airway is critically involved in angiogenesis, but such VEGF-mediated angiogeneis in the asthmatic airway is effectively reversed by corticosteroid treatment. In patients with severe COPD or severe asthma, TNF- $\alpha$, which is a pleiotropic proinflammatory cytokine that exerts its biological effects mainly by acting on the vascular endothelium, is abundant in the airway. Only in the presence of TNF- $\alpha$, IL-4/13 and IFN- $\gamma$ reciprocally regulate angiogenic-angiostatic balance through autocrine synthesis of CXCR2 and CXCR3 chemokines, respectively. Corticosteroid therapies would offer little hope for improving TNF- $\alpha / \mathrm{CXCR} 2$ chemokine-associated angiogenesis, and thus hypervascularity in severe asthma might be primarily due to TNF- $\alpha$ and CXCR 2 chemokines rather than mediation by VEGF. On the other hand, TNF- $\alpha$ associated overproductions of CXCR3 chemokines in severe emphysema might be involved in the avascularity in alveolar septa, in addition to reduction of VEGF. Moreover, TNF- $\alpha$ also plays crucial roles directly in vascular functions by regulating leukocyte recruitment into local inflamed tissues, but corticosteroid therapies would enhance these inflammatory responses on the microvessels rather than inhibit them.

Thus, TNF- $\alpha$ and CXC chemokines can be surmised to be critically associated with microvascular alterations in patients with severe pulmonary inflammatory diseases. Further studies are required to examine whether CXCR3/CXCR2 chemokines play roles in the attenuation and development of pulmonary angiogenesis in patients with severe COPD and asthma, respectively. Nevertheless, there is the possibility of microvessel-targeted treatment options in the near future for these patients, whereas ICS therapies offer little expectation for improvement of these microvascular alterations mediated by TNF- $\alpha$ and CXC chemokines.

\section{Acknowledgments}

We thank Ms. Hiromi Wakita and Mr. Shuhei Fukuda for the illustration in the figure.

\section{Disclosures}

The authors have no conflicts of interest to declare.

\section{References}

Aaron SD, Angel JB, Lunau M, et al. 2001. Granulocyte inflammatory markers and airway infection during acute exacerbation of chronic obstructive pulmonary disease. Am J Respir Crit Care Med, 163:349-55.

Abdel-Rahman AM, el-Sahrigy SA, Bakr SI. 2006. A comparative study of two angiogenic factors: vascular endothelial growth factor and angiogenin in induced sputum from asthmatic children in acute attack. Chest, 129:266-71.
Abman SH. 2001. Bronchopulmonary dysplasia:“a vascular hypothesis". Am J Respir Crit Care Med, 164:1755-6.

Addison CL, Daniel TO, Burdick MD, et al. 2000. The CXC chemokine receptor 2, CXCR2, is the putative receptor for ELR+ CXC chemokineinduced angiogenic activity. J Immunol, 165:5269-77.

Asai K, Kanazawa H, Kamoi H, et al. 2003. Increased levels of vascular endothelial growth factor in induced sputum in asthmatic patients. Clin Exp Allergy, 33:595-9.

Asai K, Kanazawa H, Otani K, et al. 2002. Imbalance between vascular endothelial growth factor and endostatin levels in induced sputum from asthmatic subjects. $J$ Allergy Clin Immunol, 110:571-5.

Barnes PJ. 2003. Chronic obstructive pulmonary disease * 12:New treatments for COPD. Thorax, 58:803-8.

Barnes PJ. 2007. New molecular targets for the treatment of neutrophilic diseases. J Allergy Clin Immunol, 119:1055-62.

Barnes PJ. 2008. Immunology of asthma and chronic obstructive pulmonary disease. Nat Rev Immunol, 8:183-92.

Barnes PJ, Pedersen S, Busse WW. 1998. Efficacy and safety of inhaled corticosteroids. New developments. Am J Respir Crit Care Med, 157:S1-53.

Bentley AM, Hamid Q, Robinson DS, et al. 1996. Prednisolone treatment in asthma. Reduction in the numbers of eosinophils, T cells, tryptase-only positive mast cells, and modulation of IL-4, IL-5, and interferon-gamma cytokine gene expression within the bronchial mucosa. Am J Respir Crit Care Med, 153:551-6.

Berry MA, Hargadon B, Shelley M, et al. 2006. Evidence of a role of tumor necrosis factor alpha in refractory asthma. $N$ Engl $J$ Med, 354:697-708.

Broide DH, Sullivan S, Gifford T, et al. 1998. Inhibition of pulmonary eosinophilia in P-selectin- and ICAM-1-deficient mice. Am J Respir Cell Mol Biol, 18:218-25.

Burdick MD, Murray LA, Keane MP, et al. 2005. CXCL11 attenuates bleomycin-induced pulmonary fibrosis via inhibition of vascular remodeling. Am J Respir Crit Care Med, 171:261-8.

Busse WW, Lemanske RF Jr. 2001. Asthma. N Engl J Med, 344:350-62.

Carlos TM, Harlan JM. 1994. Leukocyte-endothelial adhesion molecules. Blood, 84:2068-101.

Chetta A, Zanini A, Foresi A, et al. 2003. Vascular component of airway remodeling in asthma is reduced by high dose of fluticasone. Am J Respir Crit Care Med, 167:751-7.

Chetta A, Zanini A, Foresi A, et al. 2005. Vascular endothelial growth factor up-regulation and bronchial wall remodelling in asthma. Clin Exp Allergy, 35:1437-42.

Chung KF. 2001. Cytokines in chronic obstructive pulmonary disease. Eur Respir, J (Suppl 34):50s-59s.

Cotran R, Pober JS. 1990. Cytokine-endothelial interactions in inflammation, immunity, and vascular injury. J Am Soc Nephrol, 1:225-35.

Di Stefano A, Capelli A, Lusuardi M, et al. 1998. Severity of airflow limitation is associated with severity of airway inflammation in smokers. $\mathrm{Am}$ J Respir Crit Care Med, 158:1277-85.

Di Stefano A, Capelli A, Lusuardi M, et al. 2001. Decreased T lymphocyte infiltration in bronchial biopsies of subjects with severe chronic obstructive pulmonary disease. Clin Exp Allergy, 31:893-902.

Feldmann M, Maini RN. 2003. Lasker Clinical Medical Research Award. TNF defined as a therapeutic target for rheumatoid arthritis and other autoimmune diseases. Nat Med, 9:1245-50.

Feltis BN, Wignarajah D, Reid DW, et al. 2007. Effects of inhaled fluticasone on angiogenesis and vascular endothelial growth factor in asthma. Thorax, 62:314-9.

Ferrara N, Gerber HP, LeCouter J. 2003. The biology of VEGF and its receptors. Nat Med, 9:669-76.

Grashoff WF, Sont JK, Sterk PJ, et al. 1997. Chronic obstructive pulmonary disease:role of bronchiolar mast cells and macrophages. Am J Pathol, 151:1785-90.

Grumelli S, Corry DB, Song LZ, et al. 2004. An immune basis for lung parenchymal destruction in chronic obstructive pulmonary disease and emphysema. PLoS Med, 1:e8. 
Hacievliyagil SS, Gunen H, Mutlu LC, et al. 2006. Association between cytokines in induced sputum and severity of chronic obstructive pulmonary disease. Respir Med, 100:846-54.

Hardaker EL, Bacon AM, Carlson K, et al. 2004. Regulation of TNFalpha- and IFN-gamma-induced CXCL10 expression:participation of the airway smooth muscle in the pulmonary inflammatory response in chronic obstructive pulmonary disease. Faseb J, 18:191-3.

Hatfield CA, Brashler JR, Winterrowd GE, et al. 1997. Intercellular adhesion molecule-1-deficient mice have antibody responses but impaired leukocyte recruitment. Am J Physiol, 273:L513-23.

Hay DW, Sarau HM. 2001. Interleukin-8 receptor antagonists in pulmonary diseases. Curr Opin Pharmacol, 1:242-7.

Heidemann J, Ogawa H, Dwinell MB, et al. 2003. Angiogenic effects of interleukin 8 (CXCL8) in human intestinal microvascular endothelial cells are mediated by CXCR2. J Biol Chem, 278:8508-15.

Hogg JC, Chu F, Utokaparch S, et al. 2004. The nature of small-airway obstruction in chronic obstructive pulmonary disease. $N$ Engl J Med, 350:2645-53.

Holgate ST, Holloway J, Wilson S, et al. 2006. Understanding the pathophysiology of severe asthma to generate new therapeutic opportunities. J Allergy Clin Immunol, 117:496-506.

Hoshino M, Nakamura Y, Hamid QA. 2001a. Gene expression of vascular endothelial growth factor and its receptors and angiogenesis in bronchial asthma. J Allergy Clin Immunol, 107:1034-8.

Hoshino M, Takahashi M, Aoike N. 2001b. Expression of vascular endothelial growth factor, basic fibroblast growth factor, and angiogenin immunoreactivity in asthmatic airways and its relationship to angiogenesis. $J$ Allergy Clin Immunol, 107:295-301.

Howarth PH, Babu KS, Arshad HS, et al. 2005. Tumour necrosis factor (TNFalpha) as a novel therapeutic target in symptomatic corticosteroid dependent asthma. Thorax, 60:1012-8.

Issa R, Xie S, Khorasani N, et al. 2007. Corticosteroid inhibition of growth-related oncogene protein-alpha via mitogen-activated kinase phosphatase-1 in airway smooth muscle cells. J Immunol, 178:7366-75

Jakkula M, Le Cras TD, Gebb S, et al. 2000. Inhibition of angiogenesis decreases alveolarization in the developing rat lung. Am J Physiol Lung Cell Mol Physiol, 279:L600-7.

Jeffery PK. 2000. Comparison of the structural and inflammatory features of COPD and asthma. Giles F. Filley Lecture. Chest, 117 (Suppl 1):251S-60S.

Johnston SL, Pattemore PK, Sanderson G, et al. 1995. Community study of role of viral infections in exacerbations of asthma in 9-11 year old children. Bmj, 310:1225-9.

Kamath AV, Pavord ID, Ruparelia PR, et al. 2005. Is the neutrophil the key effector cell in severe asthma? Thorax, 60:529-30.

Kanazawa H, Asai K, Hirata K, et al. 2003. Possible effects of vascular endothelial growth factor in the pathogenesis of chronic obstructive pulmonary disease. Am J Med, 114:354-8.

Kanazawa H, Hirata K, Yoshikawa J. 2002. Involvement of vascular endothelial growth factor in exercise induced bronchoconstriction in asthmatic patients. Thorax, 57:885-8.

Kasahara Y, Tuder RM, Taraseviciene-Stewart L, et al. 2000. Inhibition of VEGF receptors causes lung cell apoptosis and emphysema. J Clin Invest, 106:1311-9.

Kelly M, Hwang JM, Kubes P. 2007. Modulating leukocyte recruitment in inflammation. J Allergy Clin Immunol, 120:3-10.

Laitinen LA, Laitinen A, Heino M, et al. 1991. Eosinophilic airway inflammation during exacerbation of asthma and its treatment with inhaled corticosteroid. Am Rev Respir Dis, 143:423-7.

Lasagni L, Francalanci M, Annunziato F, et al. 2003. An alternatively spliced variant of CXCR3 mediates the inhibition of endothelial cell growth induced by IP-10, Mig, and I-TAC, and acts as functional receptor for platelet factor 4. J Exp Med, 197:1537-49.

Lee CG, Link H, Baluk P, et al. 2004. Vascular endothelial growth factor (VEGF) induces remodeling and enhances $\mathrm{TH} 2$-mediated sensitization and inflammation in the lung. Nat Med, 10:1095-103.
Lee YC, Lee K. 2001. Vascular endothelial growth factor in patients with acute asthma. J Allergy Clin Immunol, 107:1106.

Liebow AA. 1959. Pulmonary emphysema with special reference to vascular changes. Am Rev Respir, Dis 80:67-93.

Majori M, Corradi M, Caminati A, et al. 1999. Predominant TH1 cytokine pattern in peripheral blood from subjects with chronic obstructive pulmonary disease. J Allergy Clin Immunol, 103:458-62.

Mann BS, Chung KF. 2006. Blood neutrophil activation markers in severe asthma: lack of inhibition by prednisolone therapy. Respir Res, 7:59.

Marx N, Mach F, Sauty A, et al. 2000. Peroxisome proliferator-activated receptor-gamma activators inhibit IFN-gamma-induced expression of the T cell-active CXC chemokines IP-10, Mig, and I-TAC in human endothelial cells. J Immunol, 164:6503-8.

Matsuda A, Fukuda S, Matsumoto K, et al. 2008a. Th1/Th2 cytokines reciprocally regulate in vitro pulmonary angiogenesis via $\mathrm{CXC}$ chemokine synthesis. Am J Respir Cell Mol Biol, 38:168-75.

Matsuda A, Orihara K, Fukuda S, et al. 2008b. Corticosteroid enhances TNF-alpha-mediated leukocyte adhesion to pulmonary microvascular endothelial cells. Allergy, (in press). DOI:10.1111/j.13989995.2008.01775.

Nagase T, Fukuchi Y, Matsuse T, et al. 1995. Antagonism of ICAM-1 attenuates airway and tissue responses to antigen in sensitized rats. $A m$ J Respir Crit Care Med, 151:1244-9.

Newton R, Holden NS, Catley MC, et al. 2007. Repression of inflammatory gene expression in human pulmonary epithelial cells by small-molecule IkappaB kinase inhibitors. J Pharmacol Exp Ther, 321:734-42.

Nicholson KG, Kent J, Ireland DC. 1993. Respiratory viruses and exacerbations of asthma in adults. Bmj, 307:982-6.

Panina-Bordignon P, Papi A, Mariani M, et al. 2001. The C-C chemokine receptors CCR4 and CCR8 identify airway T cells of allergenchallenged atopic asthmatics. J Clin Invest, 107:1357-64.

Pesci A, Balbi B, Majori M, et al. 1998. Inflammatory cells and mediators in bronchial lavage of patients with chronic obstructive pulmonary disease. Eur Respir J, 12:380-6.

Rennard SI, Fogarty C, Kelsen S, et al. 2007. The safety and efficacy of infliximab in moderate to severe chronic obstructive pulmonary disease. Am J Respir Crit Care Med, 175:926-34.

Risau W. 1997. Mechanisms of angiogenesis. Nature 386:671-4.

Rohde G, Wiethege A, Borg I, et al. 2003. Respiratory viruses in exacerbations of chronic obstructive pulmonary disease requiring hospitalisation: a case-control study. Thorax, 58:37-42.

Saetta M, Mariani M, Panina-Bordignon P, et al. 2002. Increased expression of the chemokine receptor CXCR3 and its ligand CXCL10 in peripheral airways of smokers with chronic obstructive pulmonary disease. $\mathrm{Am} J$ Respir Crit Care Med, 165:1404-9.

Sauty A, Dziejman M, Taha RA, et al. 1999. The T cell-specific CXC chemokines IP-10, Mig, and I-TAC are expressed by activated human bronchial epithelial cells. J Immunol, 162:3549-58.

Schleimer RP. 1990. Effects of glucocorticosteroids on inflammatory cells relevant to their therapeutic applications in asthma. Am Rev Respir Dis, 141:S59-69.

Seemungal TA, Harper-Owen R, Bhowmik A, et al. 2000. Detection of rhinovirus in induced sputum at exacerbation of chronic obstructive pulmonary disease. Eur Respir J, 16:677-83.

Senger DR, Van de Water L, Brown LF, et al. 1993. Vascular permeability factor (VPF, VEGF) in tumor biology. Cancer Metastasis Rev, $12: 303-24$

Silvestri M, Bontempelli M, Giacomelli M, et al. 2006. High serum levels of tumour necrosis factor-alpha and interleukin- 8 in severe asthma:markers of systemic inflammation? Clin Exp Allergy, 36:1373-81.

Spoelstra FM, Postma DS, Hovenga H, et al. 2000. Budesonide and formoterol inhibit ICAM-1 and VCAM-1 expression of human lung fibroblasts. Eur Respir, $J$ 15:68-74.

Staunton DE, Merluzzi VJ, Rothlein R, et al. 1989. A cell adhesion molecule, ICAM-1, is the major surface receptor for rhinoviruses. Cell, 56:849-53. 
Tanaka H, Yamada G, Saikai T, et al. 2003. Increased airway vascularity in newly diagnosed asthma using a high-magnification bronchovideoscope. Am J Respir Crit Care Med, 168:1495-9.

Tillie-Leblond I, de Blic J, Jaubert F, et al. 2008. Airway remodeling is correlated with obstruction in children with severe asthma. Allergy, 63:533-41.

Vrugt B, Wilson S, Bron A, et al. 2000. Bronchial angiogenesis in severe glucocorticoid-dependent asthma. Eur Respir J, 15:1014-21.
Wilson J. 2000. The bronchial microcirculation in asthma. Clin Exp Allergy, 30 (Suppl 1):51-3.

Yancopoulos GD, Davis S, Gale NW, et al. 2000. Vascular-specific growth factors and blood vessel formation. Nature, 407:242-8.

Zlotnik A, Yoshie O. 2000. Chemokines:a new classification system and their role in immunity. Immunity, 12:121-7. 
